\title{
Atopic Dermatitis and Psoriasis are Diagnosed Clinically and Treated Empirically
}

Pushkar Aggarwal (D) - Nathan L. Bowers - Suraj Muddasani ·

Alan B. Fleischer Jr. · Steven R. Feldman

Received: August 29, 2021 / Published online: February 4, 2022

(C) The Author(s) 2022

Keywords: Medical dermatology; Epidemiology; Biopsy

\section{INTRODUCTION}

Atopic dermatitis and psoriasis commonly have manifestations such as lesion morphology and location that allow for diagnoses to be based on clinical criteria [1-4]. However, sometimes there is uncertainty in the diagnosis, and clinicians can either perform a biopsy or treat empirically. The objective of this analysis is to assess whether the dogma that psoriasis and atopic dermatitis are usually diagnosed clinically is true, by determining how often atopic dermatitis and psoriasis are biopsied because of uncertainty in the clinical diagnosis.

\section{METHODS}

Data from all providers in the National Ambulatory Medical Care Survey [5] (NAMCS) from 1993 to 2016 were analyzed in SAS [6] software

P. Aggarwal ( $₫) \cdot$ S. Muddasani · A. B. Fleischer Jr. University of Cincinnati College of Medicine, 3230 Eden Ave, Cincinnati, OH 45267, USA

e-mail: aggarwpr@mail.uc.edu

N. L. Bowers · S. R. Feldman

Department of Dermatology, Wake Forest School of Medicine, Winston-Salem, NC, USA
9.4 (SAS Institute Inc, Cary, NC). NAMCS is conducted annually by the Center for Disease Control and Prevention to provide information about the use of outpatient medical care in the USA. Physicians from various medical specialties complete the survey, and a random sample of the physicians' patient visits are included [7]. Visits were stratified by those with a diagnosis of atopic dermatitis or psoriasis. Two separate analyses for each diagnosis were performed-one that included both new patient visits and follow-up visits and one with only new patient visits. This article is based on previously conducted studies/publicly available data and does not contain any new studies with human participants or animals performed by any of the authors.

\section{RESULTS}

From 1993 to 2016, 1463 survey visits with atopic dermatitis as a diagnosis were documented in NAMCS, representing 38 million (95\% confidence interval, 35-40 million) such encounters in the USA (Table 1). Four hundred ninety-four survey visits [representing 13 million (11-14 million)] had atopic dermatitis as the only diagnosis. Of these 494 visits, one (representing 24,000) had a biopsy (performed by a dermatologist). In addition, one survey visit (representing 17,000) had a diagnosis of atopic dermatitis that was "probable, 
Table 1 Atopic dermatitis (AD) and psoriasis visits in the national ambulatory medical care survey (NAMCS) from 1993 to 2016

\begin{tabular}{|c|c|c|}
\hline & $\begin{array}{l}\text { Visits in } \\
\text { NAMCS } \\
\text { (survey) }\end{array}$ & $\begin{array}{l}\text { Total visits represented by survey } \\
\text { visits }(95 \% \text { confidence interval) }\end{array}$ \\
\hline Atopic dermatitis $(\mathrm{AD})$ diagnosis & 1463 & 38 million (35-40 million) \\
\hline $\mathrm{AD}$ diagnosis with no other diagnoses & 494 & 13 million [11-14 million] \\
\hline $\begin{array}{l}\text { AD diagnosis with no other diagnoses and with a biopsy } \\
\text { performed }\end{array}$ & 1 & 24,000 \\
\hline $\begin{array}{l}\text { AD diagnosis that was "probable, questionable, or rule out" and } \\
\text { with no other diagnoses }\end{array}$ & 1 & 17,000 \\
\hline $\begin{array}{l}\text { AD diagnosis that was "probable, questionable, or rule out" and } \\
\text { with no other diagnoses and a biopsy performed }\end{array}$ & 0 & - \\
\hline New patient with $\mathrm{AD}$ diagnosis with no other diagnoses & 121 & 2.6 million [1.9-3.3 million] \\
\hline $\begin{array}{l}\text { New patient with } \mathrm{AD} \text { diagnosis with no other diagnoses and with } \\
\text { biopsy performed }\end{array}$ & 1 & 24,000 \\
\hline $\begin{array}{l}\text { New patient with } \mathrm{AD} \text { diagnosis that was "probable, questionable, } \\
\text { or rule out" }\end{array}$ & 0 & - \\
\hline Psoriasis diagnosis & 1923 & 47 million (45-49 million) \\
\hline Psoriasis diagnosis with no other diagnoses & 938 & 20 million (19-21 million) \\
\hline $\begin{array}{l}\text { Psoriasis diagnosis with no other diagnoses and with biopsy } \\
\text { performed }\end{array}$ & 10 & $195,000[0,0-271]$ \\
\hline $\begin{array}{l}\text { Psoriasis diagnosis that was "probable, questionable, or rule out" } \\
\text { and with no other diagnoses }\end{array}$ & 9 & $195,000[0,0-322]$ \\
\hline $\begin{array}{l}\text { Psoriasis diagnosis that was "probable, questionable, or rule out" } \\
\text { and with no other diagnoses and a biopsy performed }\end{array}$ & 0 & - \\
\hline New patient with psoriasis diagnosis with no other diagnoses & 164 & 3.2 million (2.8-3.6 million) \\
\hline $\begin{array}{l}\text { New patient with psoriasis diagnosis with no other diagnoses and } \\
\text { with biopsy performed }\end{array}$ & 1 & 5000 \\
\hline $\begin{array}{l}\text { New patient with psoriasis diagnosis that was "probable, } \\
\text { questionable, or rule out" }\end{array}$ & 0 & - \\
\hline
\end{tabular}

questionable, or rule out"; however, no biopsy was performed in this visit. Stratifying visits to only those with new patients resulted in 121 survey visits [representing 2.6 million (1.9-3.3 million)] with atopic dermatitis as the only diagnosis. Of these, one survey visit had a biopsy (performed by a dermatologist). None of the 121 visits had a diagnosis of atopic dermatitis that was "probable, questionable, or rule out."

Similarly, from 1993 to 2016, 1923 survey visits [representing 47 million (45-49 million)] with psoriasis as a diagnosis were documented in NAMCS (Table 1). Nine hundred thirty-eight 
survey visits [representing 20 million (19-21 million)] had psoriasis as the only diagnosis. Of these 938 visits, 10 [representing 195,000 $(118,000-271,000)]$ had a biopsy (all performed by dermatologists). In addition, of the 938 visits, nine [representing 195,000 $(68,000-322,000)]$ had a diagnosis of psoriasis that was "probable, questionable, or rule out"; however, no biopsy was performed in any of these visits. Stratifying visits to only those with new patients resulted in 164 survey visits [representing 3.2 million (2.8-3.6 million)] with psoriasis as the only diagnosis. Of these, one survey visit had a biopsy (performed by a dermatologist). None of the 164 visits had a diagnosis of psoriasis that was "probable, questionable, or rule out."

\section{DISCUSSION}

NAMCS consists of cross-sectional survey data and is dependent on physicians for accurate coding of diagnoses and procedures. Also, the data does not specify whether the visit was for a diagnostic purpose. It is also possible that a patient required a biopsy at some point in the evolution of the disease. This biopsy would not be captured in data from the initial visit. Despite these limitations, NAMCS provides reliable nationally representative data on ambulatory medical care services in the USA. Overall, in NAMCS, for all visits with atopic dermatitis as the only diagnosis, a biopsy was performed in $0.2 \%(1 / 494)$ of the visits and for new patient visits with atopic dermatitis as the only diagnosis, a biopsy was performed in $0.8 \%$ $(1 / 121)$ of visits. For all visits with psoriasis as the only diagnosis, a biopsy was performed in $1 \%(10 / 938)$ of the visits and for new patient visits with psoriasis as the only diagnosis, a biopsy was performed in $0.6 \%(1 / 164)$ of visits. Further, a biopsy was not performed in any of the survey visits for atopic dermatitis or psoriasis in which the diagnosis was "probable, questionable, or rule out" (i.e., the diagnosis was not definitive). These data confirm the dogma that a biopsy is usually not needed to make the diagnosis of psoriasis or atopic dermatitis. The clinical manifestations of these diseases are usually sufficient for diagnosis, though there may be occasions when the clinical appearance is ambiguous.

\section{ACKNOWLEDGEMENTS}

Funding. No funding or sponsorship was received for this study or publication of this article.

Authorship. All named authors meet the International Committee of Medical Journal Editors (ICMJE) criteria for authorship for this article, take responsibility for the integrity of the work as a whole, and have given their approval for this version to be published.

Author Contributions. All authors had substantial contributions to the design, analysis and drafting of the work.

Disclosures. Alan B. Fleischer Jr is an investigator for Galderma and Trevi and a consultant for Boehringer Ingelheim, Incyte, Qurient, SCM Life Science and Syneos. Steven R. Feldman has received research, speaking and/or consulting support from a variety of companies including Galderma, GSK/Stiefel, Almirall, Leo Pharma, Boehringer Ingelheim, Mylan, Celgene, Pfizer, Valeant, Abbvie, Samsung, Janssen, Lilly, Menlo, Merck, Novartis, Regeneron, Sanofi, Novan, Qurient, National Biological Corporation, Caremark, Advance Medical, Sun Pharma, Suncare Research, Informa, UpToDate and National Psoriasis Foundation. Suraj Muddasani is currently affiliated with Lincoln Medical Center, Bronx, New York, USA. Pushkar Aggarwal and Nathan L. Bowers have nothing to disclose.

Compliance with Ethics Guidelines. This article is based on previously conducted studies/ publicly available data and does not contain any new studies with human participants or animals performed by any of the authors.

Data Availability. The datasets generated during and/or analyzed during the current 
study are available in the Centers for Disease Control and Prevention and National Center for Health Statistics. NAMCS- Ambulatory Health Care Data. Ambulatory Health Care Data repository, https://www.cdc.gov/nchs/ahcd/ index.htm

Open Access. This article is licensed under a Creative Commons Attribution-NonCommercial 4.0 International License, which permits any non-commercial use, sharing, adaptation, distribution and reproduction in any medium or format, as long as you give appropriate credit to the original author(s) and the source, provide a link to the Creative Commons licence, and indicate if changes were made. The images or other third party material in this article are included in the article's Creative Commons licence, unless indicated otherwise in a credit line to the material. If material is not included in the article's Creative Commons licence and your intended use is not permitted by statutory regulation or exceeds the permitted use, you will need to obtain permission directly from the copyright holder. To view a copy of this licence, visit http://creativecommons.org/licenses/by$\mathrm{nc} / 4.0 /$.

\section{REFERENCES}

1. Reynolds M, Gorelick J, Bruno M. Atopic dermatitis: a review of current diagnostic criteria and a proposed update to management. J Drugs Dermatol. 2020;19(3):244-8.

2. Abo-Tabik M, Parisi R, Willis SC, Griffiths CEM, Ashcroft DM, Global Psoriasis Atlas (GPA). Development of clinical diagnostic criteria for chronic plaque psoriasis: an international e-Delphi study. Br J Dermatol. 2021;185(2):455-6.

3. Kim WB, Jerome D, Yeung J. Diagnosis and management of psoriasis. Can Fam Physician. 2017;63(4): 278-85.

4. Hanifin JM, Rajka G. Diagnostic features of atopic dermatitis. Acta Derm Venereol. 1980;92:44-7.

5. Centers for Disease Control and Prevention and National Center for Health Statistics. 2021. NAMCSAmbulatory Health Care Data. Ambulatory Health Care Data. https://www.cdc.gov/nchs/ahcd/index. htm

6. SAS. 9.4. SAS Institute Inc.

7. Best SR, Fakhry C. The prevalence, diagnosis, and management of voice disorders in a National Ambulatory Medical Care Survey (NAMCS) cohort. Laryngoscope. 2011;121(1):150-7. https://doi.org/10.1002/ lary.21169. 